\title{
Chapter 9 \\ User Participation and Social Integration Through ICT Technologies
}

\author{
Aristotelis Spiliotis
}

\begin{abstract}
User is one of the most important stakeholder cluster and its participation can link the end of life and early stages in the life cycle of each product when considering the adoption of a circular business model. This chapter presents the main elements of the customer engagement, as identified through a State-of-the-Art analysis carried out in the context of FENIX, as well as those electronic tools in which they will be integrated together with conventional tools for the conduction of commercial activities and the tools to facilitate the interaction with the other actors and activities of FENIX within a single access point digital platform (FENIX Marketplace). The SoA analysis identified the motivational factors that promote a greater customer engagement for the participation throughout all business routes (B2B, B2C but also C2C) applicable in the project. These strategies are improved and enhanced using benefits provided by the social media for the participation in the process. The customer involvement is directly linked to the motives provided within FENIX Marketplace.
\end{abstract}

\subsection{Customer Engagement Strategies}

Customer relation has changed over the last years drastically. Initial perceptions view the customer and the brand as discrete entities, a relationship that follows a linear interaction starting from the brand (where value is created) and finishing to the customer (an exogenous factor to the process) [1]. However, literature shows that customers can co-create value, increase competitiveness and be involved in a way to become an intrinsic factor. According to a study by Vargo and Lush [2], as well as another recent by Vivel, Beatty and Hazod [3] on critical elements of engagement strategy, name the following characteristics as essential in engaging the customer effectively:

\footnotetext{
A. Spiliotis $(\bowtie)$

Centre for Research and Technology Hellas, Hellenic Institute of Transport, 6th Charilaou-Thermi Road, PO BOX 60361, 57001 Thermi-Thessaloniki, Greece

e-mail: aspiliotis@certh.gr
} 
- Value co-creation: by allowing customers to participate in the process

- Dialogue: which contains the provision for facilitating interaction among all stakeholders and is user to increase the ability of engaging the customers

Which both initiatives are proposed to facilitate actions in specific service relationships rather than direct customer participation. Hence the digital platform of FENIX will consist of 2 main partitions, one to focus into the provision of facilitating interactions and one for the value co-creation. The above strategies are used to engage customers, which in turn, will exhibit a) community and b) transactional engagement behaviours, the first seen as a measure of participation intensity and the latter as a set of activities facilitating repurchase behaviour and strengthening commitment [4]. These behaviours are enabled through relational benefits (see §social, financial) and expressed by recognised types of manifestations which include cooperation, feedback and compliance concerning the $\mathrm{B} 2 \mathrm{C}$ interactions but also helping others and spreading positive Word-of-Mouth for the $\mathrm{C} 2 \mathrm{C}$ interactions. A general conclusion may include that strategies should be focused on providing the relevant motivational factors (intrinsic or extrinsic) that influence the user behaviour and may lead to specific engagement outcomes, such as satisfaction, loyalty and commitment. It is important to note that no specific benefits lead to engagement behaviours. Some entertainment benefits may lead the user to present either Transactional or Community behaviours.

\subsection{FENIX Digital Ecosystem and Provided Incentives}

Based on the above, it is concluded that the research model for the digital Marketplace should create an ecosystem where the customer and particular digital tools co-exist along with the provided behavioural benefits (Fig. 9.1).

Customer's manifestations require a mean (a channel) for transmitting the above messages, a platform to state their expression and a network to disseminate them. FENIX digital platform (Marketplace), with its tools, is intended to play a crucial role in all of the above requirements. The network may also be passively enhanced through social media and for that, the most popular channels have been chosen to be linked with FENIX Marketplace (Facebook, LinkedIn and twitter). Social media assists to shift control of some traditional decisions (price, promotion, etc.) to the customers, while at the same time enables customers to participate in strategic choices and co-create value. This is the basis for the creation and maintenance of the Brand Community (BC) that can perform many important actions on behalf of FENIX and hence the digital platform should provide interoperability by means of content sharing with these channels. 
Fig. 9.1 Digital ecosystem

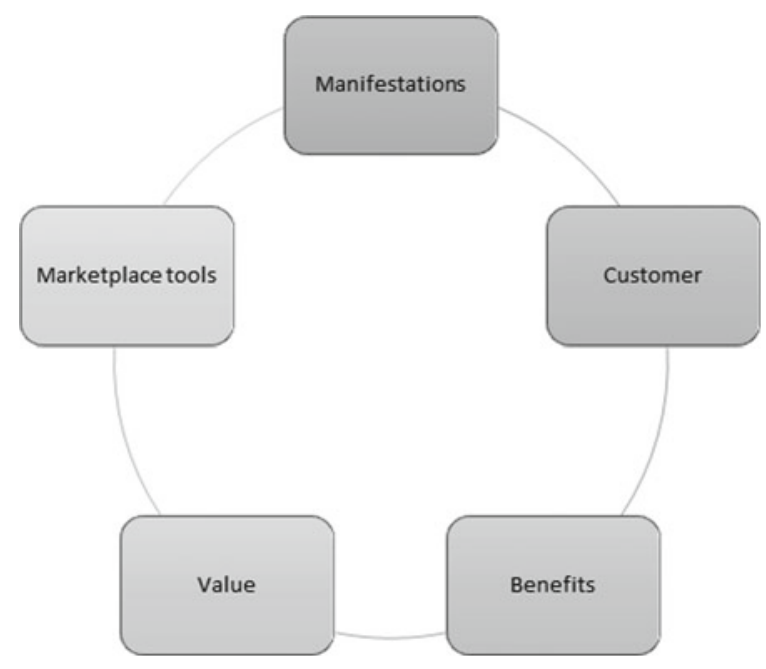

\subsubsection{Social Benefits}

Social interactions, along with the aid of the social media, helps to swift control of some traditional business activities to the customer (price, promotion, etc.) and allow user to participate in the value co-creation jointly with the brand. Social networking practices are those focusing on creating, enhancing, and sustaining ties among community members, such as welcoming, empathizing and governing [5]. Consumers often also participate in the community to seek assistance and help from other members in supported discussions lined with social conversations [6]. A social platform should be able to provide Peer-to-Peer (P2P) interactions to accommodate sharing of personal experiences, exchange influence and acquiring cognitive competencies [7]. This model may greatly influence the loyalty behavior within the online community, combined with the special ideological characteristics that FENIX attracts but also endorse recycling values, prospect for new sustainable business models, awareness on manufacturing concernment, general information sharing, etc. (Fig. 9.2).

\subsubsection{Entertainment Benefits}

Entertainment benefits are mainly provided through gamification and refer to adapting a process to have entertainment qualities of a game. Gamification is the systemic addition of game elements into services [8] such as point, badges, quests and leader boards and is distinguished from games as it does not include pure game mechanisms, but its intention is to enable intrinsic motivation associated with entertainment. Entertainment will be achieved by using the 3 core elements that evoke 


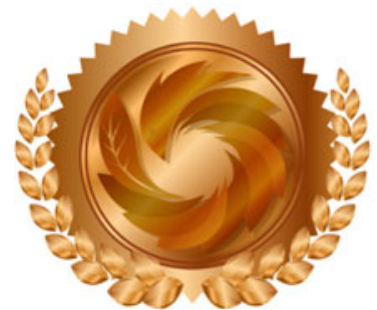

Bronze

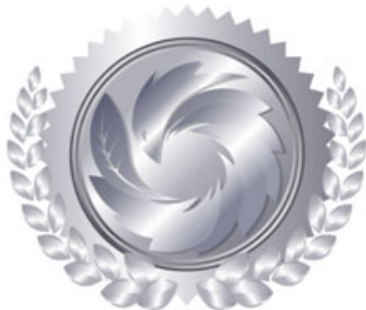

Silver

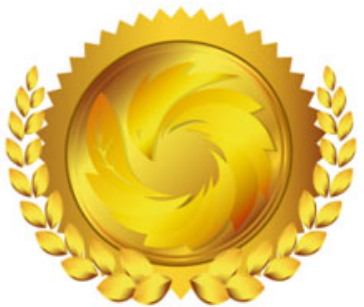

Gold

Fig. 9.2 Awarded trophies for the first 3 ranked users on the FENIX leaderboards

intrinsic motivation according to a study by Malone [9], Challenges, Curiosity and Fantasy. Gamification in FENIX will only be used as a motivational and engagement tool associated with increases in the extent and quality of effort that users put into a given task [10], but there is no intention to sustain a gaming platform.

\subsubsection{Economic Benefits}

The virtual world has provided many tools to connect not only companies but also consumers as it is already accepted that online communities allow strengthening consumer relationships and engagement [11]. Dissatisfied customers are confronted with the dilemma of taking their transaction elsewhere which will result either in giving up the economic benefits or continuing repurchasing but accepting lower levels of satisfaction, so without the economic incentives, consumers are less likely to maintain loyalty or engage in the repurchasing behavior [12]. The financial motives utilized in FENIX Marketplace are based mainly on the altruistic motive of Special offers/prices and less in Monetary compensation, as this had the smallest influence on customer's willingness to engage according to a recent study [13].

\subsection{FENIX Crowdsourcing System}

In a Crowdsourcing System, tasks are distributed to a group of users for carrying them out, hence a successful system should firstly have available a network of people which can interact and share information in direct and fast way to form a virtual online community and secondly to match the demographics and the special characteristics of the available population to the core values of the project. The motivational factors (intrinsic or extrinsic) that influence the performance of the system have already been identified to the appropriate engagement strategies. 


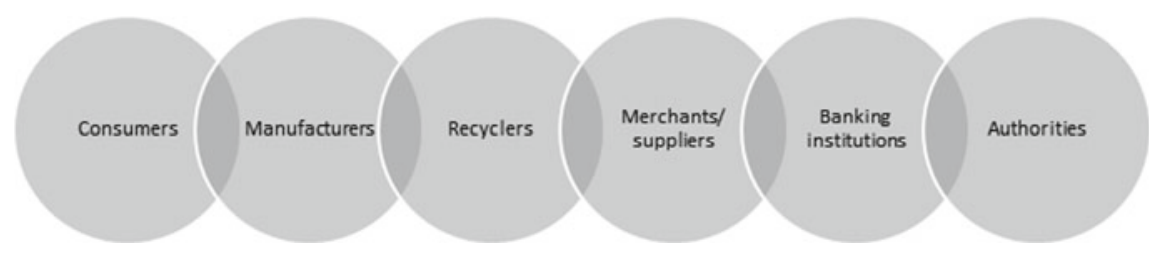

Fig. 9.3 FENIX stakeholder clusters

\subsubsection{Role of Human Users}

Users in the Marketplace are classified into 2 main categories in each of them there may be more subcategories based on the special characteristics (skills and willingness to get involved) of each user: (i) the Task Providers and (ii) the Task Contributors. The Forum presented in this chapter forms the place of the FENIX virtual community in which a community of users will be configured, with the appropriate features and interests to constitute the human resource of the FENIX crowdsourcing system. Within the presented research model, highly engaged customers is an essential part of the circular process in value co-creation as to provide feedback, participate in product design or assembly, trade reused items or feed the production plants with new raw materials from waste. The potential users have been defined from the initial objectives of the project and validated throughout the consortium meetings and workshops. Figure 9.3 shows the applicable clusters, which is by no means restricted to them, but it may rather be expanded to include additional actors in the future.

\subsubsection{Crowdvoting System}

Voting systems typically require from the requester to select one or more answers from a number of choices (provided by other crowdsourcing workers). Users can upvote, downvote or not vote so that answers and questions can be ranked among the community. Such mechanisms assist to evaluate the quality of data since the contributors are not experts and usually their incentives are not aligned with those of the requesters. Voting is also required to evaluate other behaviours and actions (Fig. 9.4).

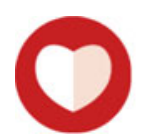

Like

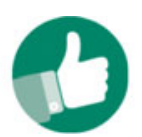

Thanks

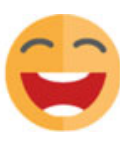

Laugh

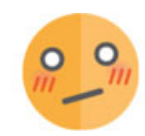

Confused

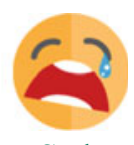

Sad

Fig. 9.4 FENIX crowdvoting emoticon system 


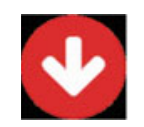

Downvote

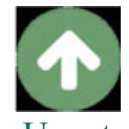

Upvote

Fig. 9.5 Two-way voting system

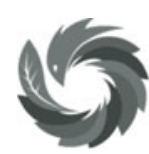

$\mathrm{Bad}$

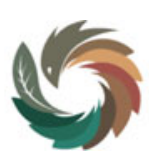

Poor

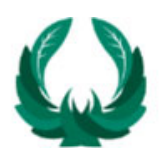

Neutral

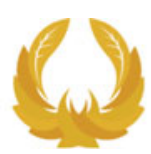

Good

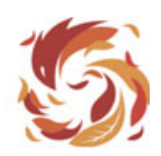

Excellent

Fig. 9.6 Community reputation recognition

Voting system uses 2 types of regular voting, one for the evaluation of the content (Figure 9.5 which also includes the offered products for sale/ trading). The "Like", "Thanks" and "Laugh" vote gives Positive (+1) reputation, the "Confused" gives Neutral reputation and the "Sad" gives Negative $(-1)$ reputation. On the same way, "Upvote" gives Positive $(+1)$ reputation and "Downvote" gives Negative $(-1)$ reputation for the user profile (Fig. 9.6). A flag warning can also be used to directly report activities that deviate from the regulations.

With respect to the voting user profiles are classified based on their community reputation (qualitative dimension) and their community ranking (deputizes the extend of the user's activity). A newly introduced member is ranked as "Neutral". It is evident the gamification elements that will boost user entertainment through these crowdsourcing activities.

\subsection{FENIX Pre-identified Goals and Link to Developed Mechanisms}

A number of crowdsourcing mechanisms have been identified by analysing the three key elements of Web-based crowdsourcing [14]: the crowd, the outsourcing model and advanced internet technologies to be used. The demographics and the purpose of crowdsourcing has been studied extensively and below the most important goals of are captured, matched with the most suitable solution approaches, the triggering factors and the platform on which it is intended to function. These functions and the appropriate mechanisms have been developed in the context of WP5 and presented in the next section (Table 9.1).

So, the following list presents the main goals which should be aimed at fulfilment by the functions of the digital Marketplace: 
Table 9.1 Main objectives of WP5 coupled with an appropriate CS mechanism

\begin{tabular}{|c|c|c|c|}
\hline No. & Aim & CS mechanism & Operating platform \\
\hline 1 & Populating item availability & $\begin{array}{l}\text { Customer generated content } \\
\text { platform (upload own } \\
\text { designs, items, etc.) }\end{array}$ & Marketplace \\
\hline 2 & $\begin{array}{l}\text { Optimizing } \\
\text { demand-production }\end{array}$ & $\begin{array}{l}\text { Allow and promote mass } \\
\text { orders, DSS link with } \\
\text { sensors, etc. }\end{array}$ & Marketplace/DSS \\
\hline 3 & Main and secondary market & Trading platform & Marketplace \\
\hline 4 & Product-service evaluation & Enable a crowdvoting system & $\begin{array}{l}\text { User forum and } \\
\text { Marketplace }\end{array}$ \\
\hline 5 & Minimizing fraud/scam risk & $\begin{array}{l}\text { Use of crowdvoting system } \\
\text { for reporting inappropriate } \\
\text { activities }\end{array}$ & $\begin{array}{l}\text { User forum and } \\
\text { marketplace }\end{array}$ \\
\hline 6 & General problem solving & $\begin{array}{l}\text { Open content } \\
\text { communication tool }\end{array}$ & User forum \\
\hline 7 & $\begin{array}{l}\text { Identifying future market } \\
\text { trends }\end{array}$ & $\begin{array}{l}\text { Monitor customers activity } \\
\text { and feedback, but also allow } \\
\text { information fishing through } \\
\text { custom polls. Also use data } \\
\text { mining in the search bar }\end{array}$ & $\begin{array}{l}\text { User forum-Data mining } \\
\text { and Polls, } \\
\text { marketplace_Data mining }\end{array}$ \\
\hline 8 & Attract new customers & $\begin{array}{l}\text { Allow interactivity with } \\
\text { popular social media for } \\
\text { dissemination }\end{array}$ & $\begin{array}{l}\text { User forum and } \\
\text { marketplace }\end{array}$ \\
\hline 9 & $\begin{array}{l}\text { Promote and support the } \\
\text { creation of new innovations }\end{array}$ & $\begin{array}{l}\text { Provide a platform where } \\
\text { individuals can set custom } \\
\text { challenges and call for } \\
\text { contributors }\end{array}$ & $\begin{array}{l}\text { Marketplace/open } \\
\text { innovation platform }\end{array}$ \\
\hline
\end{tabular}

- Populating the availability of new items

- Optimising demand-production

- Main and secondary Market

- Product-service and content evaluation

- Minimising fraud/scan activity

- General problem solving

- Identifying future market trends

- Attract new customers

- Promote and support the creation of new innovations.

\subsection{The Digital Marketplace}

The Marketplace has been designed to form a very powerful tool which will host the appropriate functions that satisfy and promote both the activities of FENIX, as well as the customer engagement strategies. The main platforms included within are: 
- The Marketplace

- A Forum

- A Showroom

- Customer's generated content page

- An Open Innovation Platform (OIP).

which are accessed through a single access point, using a FENIX account or use an existing account from Facebook or Google. Other minor functions that operate horizontally exist and function in addition to the above, but with significant importance. In the following sections, a presentation of each platform and functions is included. Access to the application can be obtained through the weblink: https://forum.fenixapps.eu/.

\subsubsection{Forum}

The user forum is intended to form the online social community of FENIX, connects users through Peer-to-Peer interactions and it includes the feedback collection mechanisms. It is associated mainly to the social benefits provided towards customer engagement, but also encompasses entertainment benefits incorporated within horizontally applied functions (e.g., crowdvoting). Users are separated into the following groups that represent a membership which is accompanied by consistent privileges and responsibilities within the online society (administrators, moderators, registered users and visitors). Administrators manage technical details and other core operations of the platform, moderators are granted access to monitor the content of posts and threads, while registered users can post content and participate in online activities as well as to be members of the FENIX social groups. The unregistered users can only view and read content. Social groups are formed to represent the active social clustering (see Sect. 9.3.1) within this ecosystem and their members share very close interests and background and hence enhance the social cohesion among users. This characteristic together with the integration of content exchange with popular social media is expected to expand the competence of the digital ecosystem and increase the Word-of-Mouth activities, which in turn is usually accompanied by other desired crowdsourcing activities such as advertising and initiation. Other groups can be freely created by the users. The Forum section is divided between 2 sub-sections, one which is related to the forum itself and the engaging of users in free text dialogues and another one called Reviews, which is used to capture in quantitative form the feedback of the users (Fig. 9.7).

In the first section users can share any content of their interest with the community, make comments, provide review and develop discussions with other members through open discussion topics and threads and aims to achieve the goals set for the product/service evaluation (Table 9.1, No. 4) and general problem solving (Table 9.1, No. 6). Additionally, in this section partners of FENIX consortium have created threads corresponding to the scientific fields and topics covered by the project to 


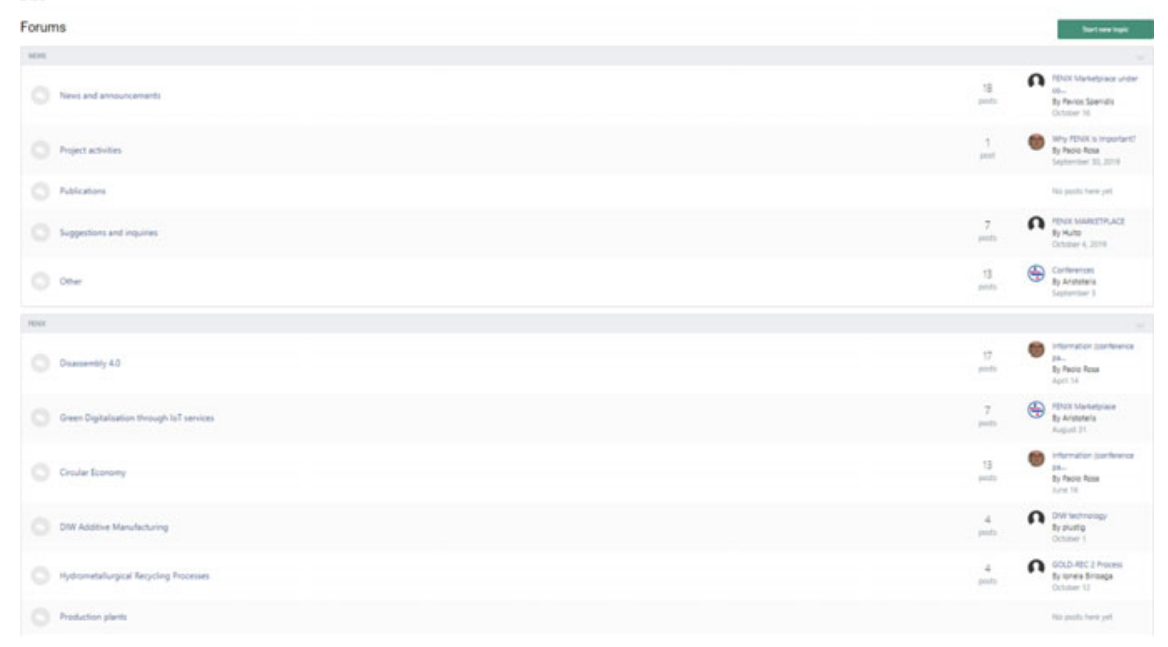

Fig. 9.7 Forum section overview

inform users about their activity, special thematic information and engage in direct dialogue throughout a "Questions and Answers" section in each topic. Every post in this section can be subjected to voting using the horizontally applied crowdvoting mechanism (Sect. 9.3.2) and share it through the most popular social media for dissemination and word-of-mouth. The Review section utilizes active polls in which users can participate with quantitative input to extract fast and easy-to-use feedback. Through the processing of these results stakeholders of FENIX may easily identify the potential of a product in the market penetration and even produce significant insights about future market trends based on the stated preferences of the users (Fig. 9.8).

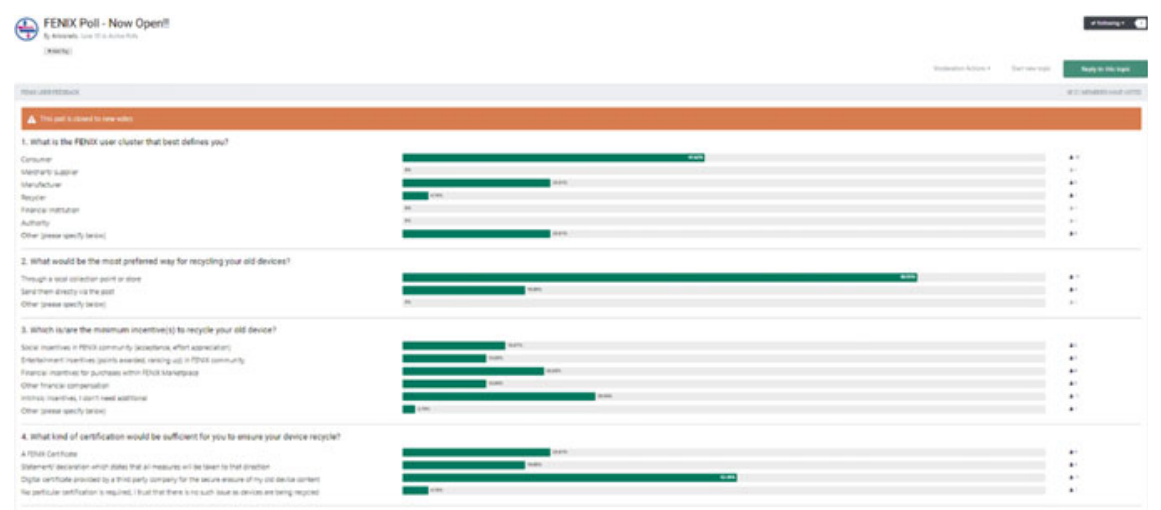

Fig. 9.8 Example of a finished review thread. Quantitative results are produced automatically 


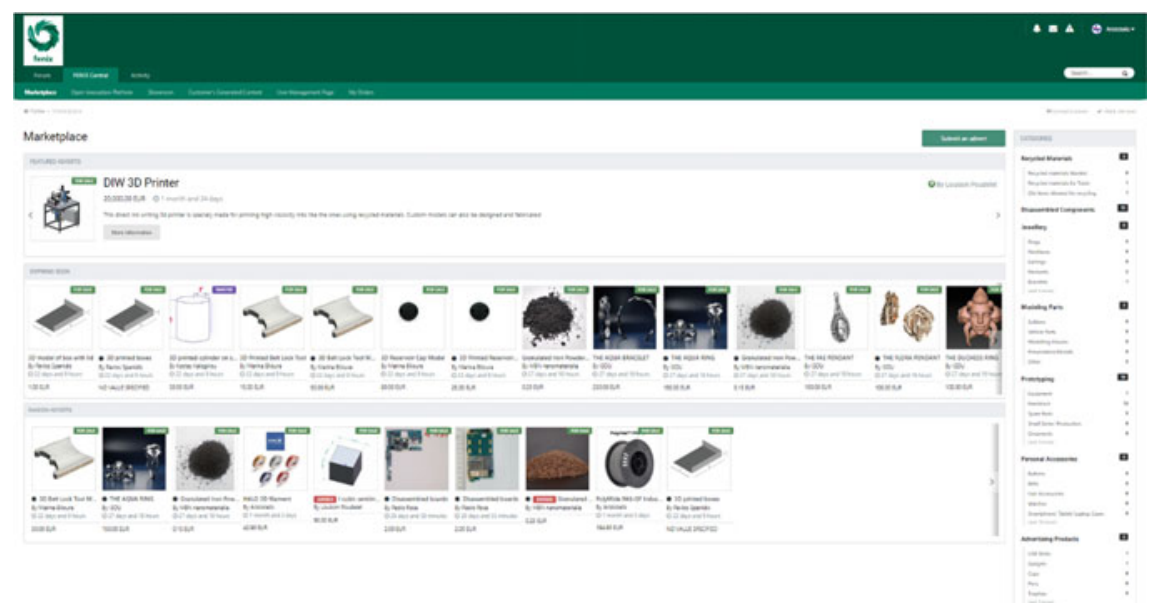

Fig. 9.9 FENIX marketplace main trading portal interface

\subsubsection{The Main Marketplace}

This serves as the main trading place of FENIX ecosystem (goals set in Sect. 9.4). Trading is strictly performed through financial interaction, but users can also choose to exchange items or set other requirements based on prior mutual consultation. The interface comprises of a list of products either new or second hand and services offered within the FENIX business model. Several filters will be available as an option for the user to apply his/her particular search preferences (product or service, new item or second hand, sorting order by newest, price, popular, etc.) (Fig. 9.9).

When selecting an item, the user is directed to the item page where additional options can initialize horizontal functionalities such as payment methods to proceed to the purchase of the item, start conversation with the seller to engage in negotiations, ask questions about the item, rate it and many more. Also, this platform may be used by the users to upload their own items in order to become active members of the business model by selling/trading old items for recycling or to create secondhand items for sell and thus extend the life cycle of a product or even link the end of life to the early stages of new products (recycled items will provide recycled raw material for the construction of new throughout FENIX use cases).

\subsubsection{Showroom}

In the Showroom, all the evaluated services, products, content and activity are displayed in ranking order, the best of which occupy prominent and distinguished positions on the screen. This is mainly an entertainment element which promotes 


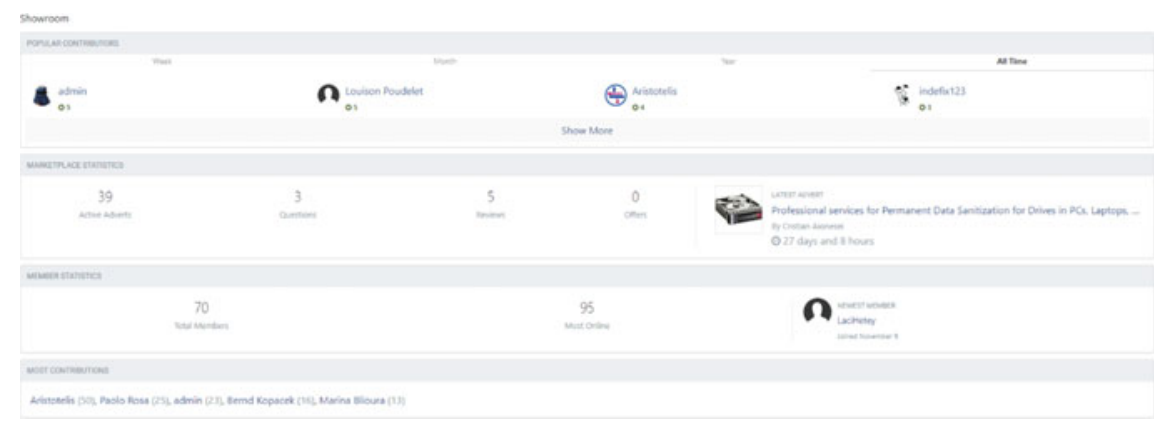

Fig. 9.10 Member contribution leaderboards

users into a productive contest among them, but also serves the social incentives through recognition for their contribution to the FENIX community (Fig. 9.10).

The above ranking makes evident the user's bond with the online community. Three different leaderboards are produced regularly to cover activity related to: (a) Reputation, (b) Content created and (c) Most posts, while virtual trophies (gold, silver and bronze) are awarded for the first positions.

\subsubsection{Customer's Generated Content}

In this platform all the uploaded content by the users will be available so that member's content can be easily retrieved from the respective database. It is a digital Marketplace with similar interface to the main Marketplace (Sect. 9.5.2), with the difference being that tradable content in this section is linked to the individual effort of the users towards value co-creation. Materials or immaterial work or services are solely user generated and participation has a direct financial incentive as designs, for example, or other services can be purchased in return for a financial profit (Fig. 9.11).

\subsubsection{Open Innovation Platform}

FENIX Open Innovation Platform (OIP) is the virtual place where the needs of the various stakeholders can meet, and match challenges defined by Task Providers to a pool of Task Contributors. Within this platform any user can set up a new task by defining the title together with the description of the requested input, upload related material and fill in the available timeframe for submitting proposals (Fig. 9.12).

The contributors will be awarded a price based on social, financial or entertainment incentives. This platform will ensure that new innovations will continue to take place by utilizing crowdsourcing through rewards and FENIX platform will provide a direct link to the business chain. 


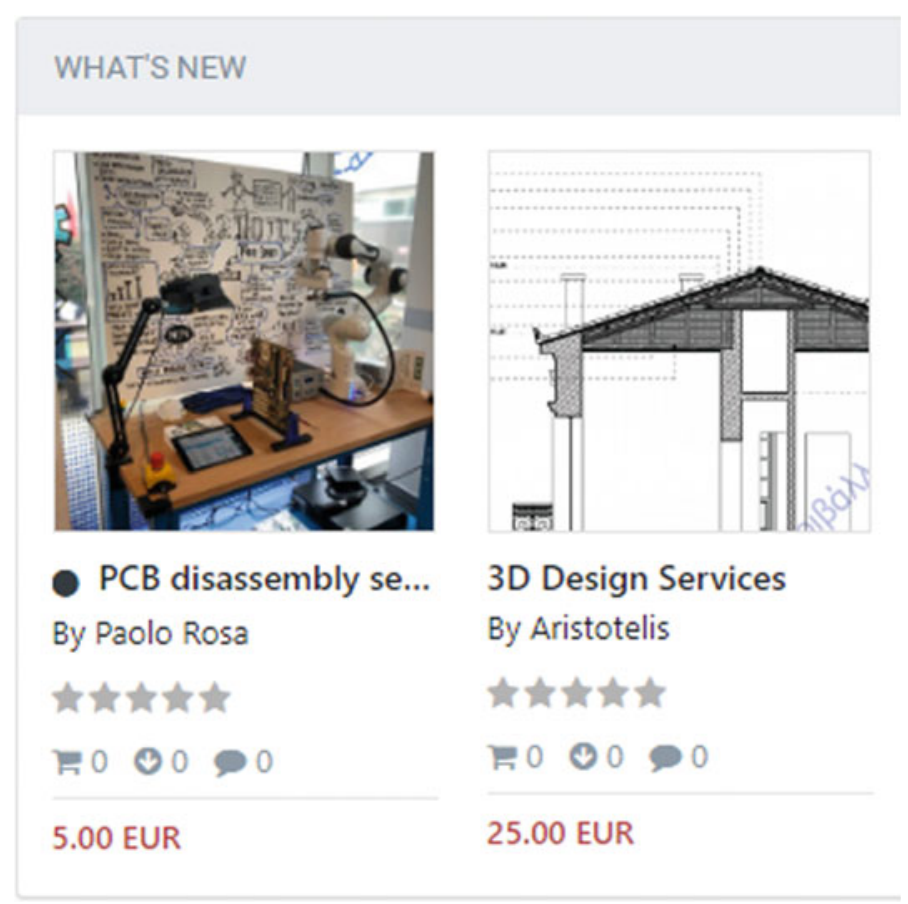

Fig. 9.11 Advertisements on the user generated content section

\subsubsection{Other Horizontally Applied Functions}

Some functions are applied horizontally, which means that can be found in 2 or more sections/ parts of the Marketplace. One such function is the algorithm that scans the content within the whole platform, to identify activity related to fraud or inappropriate content. Of course, this goal is also served and enhanced by the activity of the Moderators and Admins of the platform. In addition, crowdsourcing is utilized through the crowdvoting system or by a special review system that uses flags. Issuing of a flag leads to the direct examination by the admins of the warning, who then take actions to ensure the smooth operation of the application. Very low evaluation points also result in the examination by the admins for possible inappropriate activity, e.g., task provider does not rank contributors ethically to avoid the fee payment. Another function is the data mining mechanism. The intention of this application is to capture, anonymously and in accordance with the GDPR rules, what the users are searching in the search box. This will produce a database where useful conclusions can be drawn for the user needs and the market trends. 


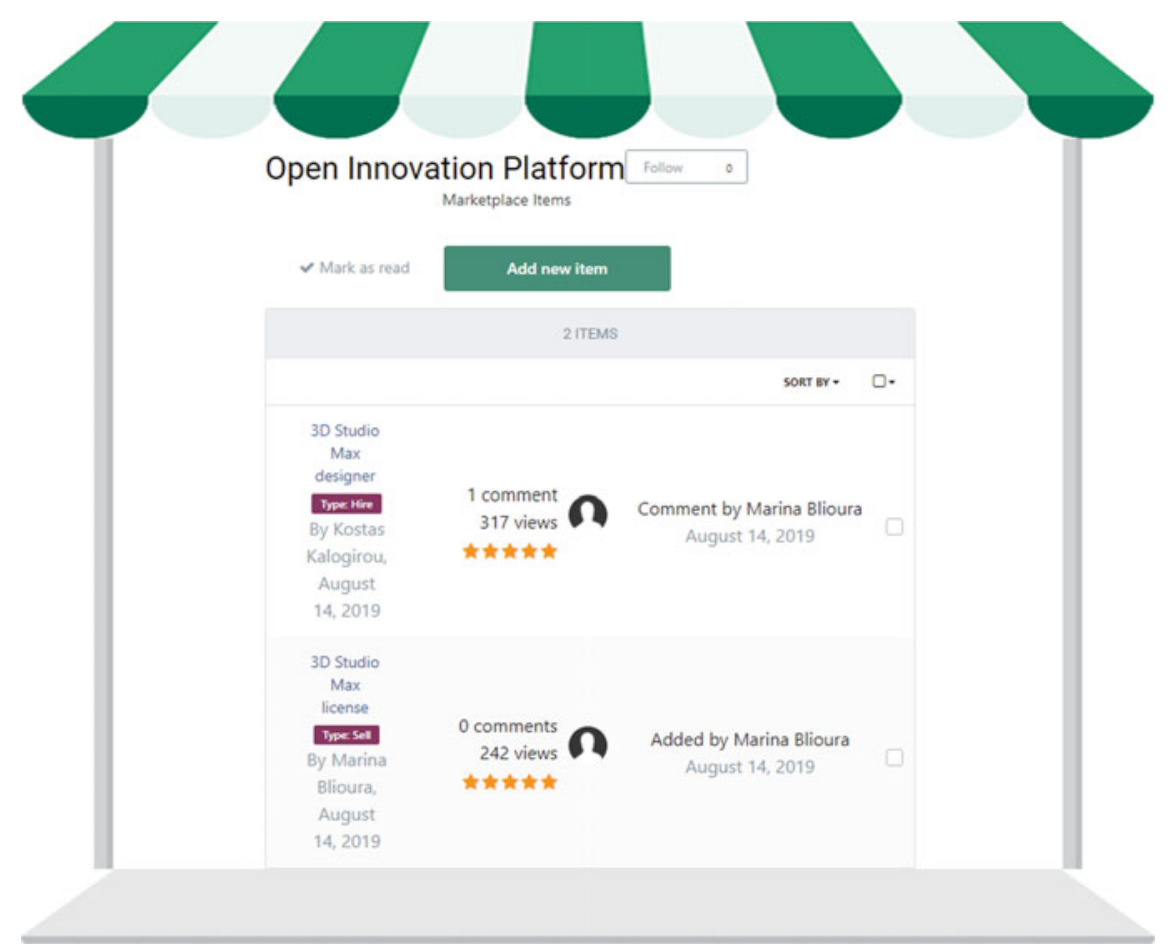

Fig. 9.12 FENIX open innovation platform interface

\subsection{Conclusions}

A State-of-the-Art analysis was carried out to identify the key enabling mechanisms of Customer Engagement associated with the behavioural manifestations based on the types of the perceived benefits (social, entertainment, economic). Having defined the appropriate crowdsourcing elements for the respective circular business model, as well as the respective incentives, a powerful Marketplace tool was presented which integrates those functions. The User Forum part of this tool enables the formation of an online community by supporting free text content to generate social activity and hence strengthen bonds between members; a poll section will be used to capture the quantitative feedback from the users. On the other hand, the main part of the Marketplace (called again Marketplace) aims to support the economic interactions between the different stakeholders (B2B, B2C and C2C) and host the most important crowdsourcing elements presented in this paper. Those have been framed by ancillary applications to enhance the effectiveness towards the implementation of a truly innovative cyclical economy business model. 


\section{References}

1. Deshpande, R. (1983). "Paradigms lost": On theory and method in research in marketing. Journal of marketing, 47(4), 101-110.

2. Vargo, S. L., \& Lusch, R. F. (2008). Service-dominant logic: continuing the evolution. Journal of the Academy of marketing Science, 36(1), 1-10.

3. Vivek, S. D., Beatty, S. E., \& Hazod, M. (2018). If you build it right, they will engage: A study of antecedent conditions of customer engagement. In Customer engagement marketing (pp. 31-40).

4. Dovaliene, A., Masiulyte, A., \& Piligrimiene, Z. (2015). The relations between customer engagement, perceived value and satisfaction: the case of mobile applications. Social and Behavioral Sciences, 213, 659-664.

5. Schau, H. J., Muñiz, A. M., \& Arnould, E. J. (2009). How brand community practices create value. Journal of marketing, 73(5), 30-51.

6. Dholakia, U. M., Blazevic, V., Wiertz, C., \& Algesheimer, R. (2009). Communal service delivery: How customers benefit from participation in firm-hosted virtual P3 communities. SSRN Electronic Journal, 12(2), 208-226.

7. Lusch, R. F., \& Vargo, S. L. (2006). Service-dominant logic: reactions, reflections and refinements. Journal of Marketing theory, 6(3), 281-288.

8. Huotari, K., \& Hamari, J. (2012). Defining gamification: a service marketing perspective. In 16th international academic MindTrek conference.

9. Malone, T. W. (1980, September). What makes things fun to learn? Heuristics for designing instructional computer games. In Proceedings of the 3rd ACM SIGSMALL symposium and the first SIGPC symposium on Small systems, Palo Alto, California (pp. 162-169).

10. Mekler, E. D., Brühlmann, F., Tuch, A. N., \& Opwis, K. (2017). Towards understanding the effects of individual gamification elements on intrinsic motivation and performance. Computers in Human Behavior, 71, 525-534.

11. Algesheimer, R., Dholakia, U. M., \& Herrmann, A. (2005). The social influence of brand community: Evidence from European car clubs. Journal of marketing, 69(3), 19-34.

12. Zheng, X., Xiang, L., Liu, I., \& Zhang, H. (2012). Enhancing consumer engagement in online shopping platforms through economic incentives. In Proceedings of the Eighteenth Americas Conference on Information Systems. AMCIS 2012 Proceedings, Seattle, Washington.

13. Fernandes, T., \& Remelhe, P. (2016). How to engage customers in co-creation: customers' motivations for collaborative innovation. Journal of Strategic Marketing, 311-326.

14. Saxton, G. D., Oh, O., \& Kishore, R. (2013). Rules of crowdsourcing: Models, issues, and systems of control. Information Systems Management, 2-20.

Open Access This chapter is licensed under the terms of the Creative Commons Attribution 4.0 International License (http://creativecommons.org/licenses/by/4.0/), which permits use, sharing, adaptation, distribution and reproduction in any medium or format, as long as you give appropriate credit to the original author(s) and the source, provide a link to the Creative Commons license and indicate if changes were made.

The images or other third party material in this chapter are included in the chapter's Creative Commons license, unless indicated otherwise in a credit line to the material. If material is not included in the chapter's Creative Commons license and your intended use is not permitted by statutory regulation or exceeds the permitted use, you will need to obtain permission directly from the copyright holder. 